\title{
A Qualitative Study of Hard Decision Making in Managing Global Software Development Teams
}

\author{
Ángel García-Crespo ${ }^{1}$, Ricardo Colomo-Palacios ${ }^{1}$, Pedro Soto-Acosta ${ }^{2}$, and Marcos Ruano-Mayoral ${ }^{3}$ \\ ${ }^{1}$ Computer Science Department, Universidad Carlos III de Madrid, Madrid, Spain \\ ${ }^{2}$ Department of Management \& Finance, Universidad de Murcia, Murcia, Spain \\ ${ }^{3}$ EgeoIT, Madrid, Spain
}

\begin{abstract}
We empirically explored the implication of hard decisions in the context of the management of global software development (GSD) teams. We hypothesized and empirically tested our belief that hard decision making in conventional development projects is very similar to GSD and differences arise from the nature of the relationship and the ranking of issues. Findings from a Delphi study illustrated our approach and shed some light into the management of GSD teams.
\end{abstract}

Keywords global software development teams; hard decisions; qualitative study; trust

\section{INTRODUCTION}

Due to increasing globalization tendencies in organization environment, Software Development is evolving from a single site development to multiple localization team environments (Hernández-López, Colomo-Palacios, García-Crespo, \& SotoAcosta, 2010). Thus, Software Development evolved in order to adopt some Globalization characteristics; as a result, a new field called Global Software Development (GSD) emerged to cover specific aspects of global distributed software development (Oshri, Kotlarsky, \& Willcocks, 2007). Intrinsically, GSD teams are like any other team and, therefore, need to be managed. The task of managing a software project can be an extremely complex one, drawing on many personal, team and organizational resources (Rose, Pedersen, Hosbond, Kraemmergaard, 2007). Given that management implies decision-making, managing GSD teams also implies new decisions in new scenarios. And some of the decisions that every software development project manager must make can be tagged as Hard Decisions. According to Clemen (1996) and Clemen and Reilly (2001) hard decisions are characterized by:

1. the complexity of the problem;

2. uncertainty inherent in the situation;

Address correspondence to Ricardo Colomo-Palacios, Computer Science Department, Universidad Carlos III de Madrid, Av. Universidad 30, Leganés 28911, Madrid, Spain. E-mail: ricardo. colomo@uc3m.es
3. the decision-maker being interested in working towards multiple objectives but progress in one direction impeding progress in others;

4. different perspectives leading to different conclusions.

Taking into account the crucial importance of GSD, the aim of this article is to find out which managerial decisions taken in GSD are different from the traditional ones. This goal is aimed to be reached by means of qualitative research, namely the Delphi method.

\section{GLOBAL SOFTWARE DEVELOPMENT TEAMS}

Software development is an intense human capital activity, more intense in intellectual capital (Sommerville \& Rodden, 1996). Back in the nineties, organizations seeking lower costs and access to skilled resources began to experiment with remotely located software development facilities (Prikladnicki, Nicolas Audy \& Evaristo, 2003; Lytras, Sakkopoulos, \&Ordóñez de Pablos, 2009).

As a result, software development became a multi-site, multicultural, globally distributed undertaking. Globalization of software development introduced a great deal of complexity in an already complex process (Treinen \& Miller-Frost, 2006). Today, more software projects are run in geographically distributed environments, and global software development is becoming a norm in the software industry (Damian \& Moitra, 2006). In this scenario, firms developing or maintaining software products cannot ignore global software development's impact (Cusick \& Prashad, 2006). Thus, according to Herbsleb and Moitra (2001), GSD causes a profound impact on the way the products are conceived, designed, constructed, tested, and delivered to customers.

Working in a global context has its advantages, but it also has drawbacks (Ebert \& De Naeve, 2001). On the plus side, many organizations have distributed software development across geographies to capitalize on global resource pools, attractive cost structures, and round-the-clock development to achieve cycle-time acceleration and cater to local markets (Damian 
\& Moitra, 2006). However, working on a globally distributed project means operating costs for planning and managing people, along with language and cultural barriers. It also creates jealousy as the more expensive engineers (who are afraid of losing their jobs) are forced to train their much cheaper counterparts (Ebert \& De Naeve, 2001; Lytras \& Ordóñez de Pablos, 2007, 2008a, b, Ordóñez de Pablos, 2002; Rodríguez and Ordóñez de Pablos, 2003)

Not in vain, in addition to the issues of software development teams, the geographical distribution inherent to virtual teams carries several problems that arise from two factors inherent to the distribution; the distance between team members and the dependence of the necessary technology to allow members to communicate (Hinds \& Bailey, 2003). Thus, according to Herbsleb (2007), the fundamental problem of GSD is that many of the mechanisms that function to coordinate the work in a colocated setting are absent or disrupted in a distributed project. This author states that the vision of the desired future of global development, shared by many, would to be to have the following capabilities:

- use available resources independently of geographic location

- plan practices and technology to support the level of coordination accurately anticipated to be required among sites

- achieve shared understanding of requirements

- measure the "fit" of a software architecture with the organization that will build the system, and have a set of known, effective tactics for improving the fit

- effectively manage change.

The importance of GSD management has led to a huge effort in the art and science of organizing and managing globally distributed software development, but there is still a significant understanding to be achieved, methods and techniques to be developed, and practices to be evolved before it becomes a mature discipline (Damian \& Moitra, 2006). Following this path, this article presents a study focused on how GSD managerial hard decision making differs from the traditional models by means of the application of a Delphi technique.

\section{HARD DECISION-MAKING IN GSD: A QUALITATIVE STUDY}

In order to find out if hard decision-making in the management of GSD teams is different from the traditional ones a Delphi study was designed and applied. In what follows, the method, sample, results and discussion are depicted.

\section{Method}

The Delphi method attempts to obtain consensus from a group of experts using repeated responses of questionnaires and controlled feedback. The objective of this Delphi study was to identify an initial set of hard decisions in GSD management and for every hard decision, three issues that are relevant to GSD teams, compared with conventional development teams. Given that, the focus of information systems research shifts from technological to managerial and organizational issues, qualitative research methods become increasingly useful (Myers, 1997) and the use of Delphi method is indicated to reach the aim of the study.

The Delphi Method, developed by Dalkey and Helmer (1963), has been widely used to obtain a consistent flow of answers through the results of questionnaires. This method originated in a series of studies that the RAND Corporation conducted in the 1950s (Okoli \& Pawlowski, 2004), and is an expert opinion survey method with three features (Hsu, Lee, \& Kreng, 2010): anonymous response, iteration and controlled feedback and finally statistical group response. As qualitative research in the information systems arena is increasing (Klein \& Myers, 1999), the use of Delphi studies in information systems is also widespread (e.g., Holsapple \& Joshi, 2002; Keil, Tiwana, \& Bush, 2002; Lai \& Chung, 2002; Moløkken-Østvold \& Jørgensen, 2004; Nevo \& Chan, 2007; Schmidt, Lyytinen, Keil, \& Cule, 2001).

A panel of experts was selected in order to perform the Delphi. Participants were carefully selected from organizations that apply GSD. Demographic information was collected from each panelist, establishing that $\mathrm{s} / \mathrm{he}$ had participated as a project manager in, at least, one IT project. Each expert was asked to record hard decisions to be taken in the management of GSD along with three features that makes this process different from the traditional ones (Phase 1). After that, individual responses were collected and aggregated, leaving just five Hard Decisions and three features (Phase 2).

In Phase 1, the panelists were asked to select four hard decisions related to GDP and two issues about these decisions that are particular to GDP. In Phase 2, panelists were presented with an ordered list of five hard decisions from Phase 1. The ordering of the hard decisions was based upon the percentage of panelists who selected each decision in Phase 1. Thus, based on feedback from the group's initial selection process, the panelists were then asked to rank each item and factor. At the end of Phase 2, a mean rank for each factor was computed, and Kendall's coefficient of concordance (W) was calculated to determine the degree of consensus among the panelists (Schmidt, 1997) according to decisions and factors. This statistic assesses the overall degree of agreement in a set of rankings given by several individuals (Siegel, 1956, pp. 229-239). Specifically, Schmidt et al. (2001) proposed that strong consensus exists for $\mathrm{W}>=0.7$; moderate consensus for $\mathrm{W}=0.5$; and weak consensus for $\mathrm{W}<0.3$.

\section{Sample}

The sample was composed of 25 panelists, each of whom was selected on the basis of his/her previous experience in GDP. Nine were women (36\%) and 16 men (64\%). The average age of 
the sample was 37.1. On average, the users on the panel had 17 years of experience. Delphi panel members were from organizations varying in size from 50 to 6,000 employees worldwide, all working as IT project manager in IT related companies.

\section{RESULTS}

Table 1 shows the results of the Hard Decisions provided by experts ranked according their frequency.

Given that Delphi was designed to collect responses from hard decisions as well as factors, Table 2 shows these factors taken from panelists' responses.

In Phase 2, panelists were presented with an ordered list of decisions from the results obtained in Phase 1 and presented in Tables $1 \& 2$. The ordering of the decisions and factors was based upon the percentage of panelists who selected each hard decision in Phase 1. Kendall's coefficient of concordance (W) was computed to assess whether there was significant agreement on the rank order among participants. The responses of the panelist were concordant (Kendall's coefficient of concordance, $\mathrm{W}=0.778, \mathrm{n}=25, \mathrm{P}<0.01)$ in the case of hard decisions and so does in the case of factors related to such decisions (Kendall's
TABLE 1

Hard decisions identified by Delphi participants

\begin{tabular}{lr}
\hline Decision & $\#$ \\
\hline Partner-Supplier election & 24 \\
Work packages assignation & 18 \\
Choose coordination & 15 \\
$\quad$ mechanisms \& tools & \\
Firing supplier & 14 \\
Methodology selection & 10 \\
Selecting internal personnel & 6 \\
Others & 13 \\
TOTAL & 100 \\
\hline
\end{tabular}

coefficient of concordance, $\mathrm{W}=0.610, \mathrm{n}=25, \mathrm{P}<0.01$. Rank results of decisions are displayed in Table 3.

The results shown in Table 3 are found to be similar to the ones in Tables 1 and 2, since the hard decisions have been

TABLE 2

Hard decisions and differential factors identified by Delphi participants

\begin{tabular}{|c|c|c|}
\hline Decision & Aspect & \# \\
\hline \multirow[t]{4}{*}{ Partner-Supplier election } & Trust & 23 \\
\hline & Software Process Maturity & 9 \\
\hline & Lack of trust in references & 7 \\
\hline & Legal constraints & 5 \\
\hline \multirow{4}{*}{$\begin{array}{l}\text { Work packages } \\
\text { assignation }\end{array}$} & Software and Task dependencies & 13 \\
\hline & $\begin{array}{l}\text { Need to preserve core competency in one of the } \\
\text { companies }\end{array}$ & 12 \\
\hline & Trust & 7 \\
\hline & $\begin{array}{l}\text { Lack of knowledge about real competences from } \\
\text { partners }\end{array}$ & 4 \\
\hline \multirow{4}{*}{$\begin{array}{l}\text { Choose coordination } \\
\text { mechanisms \& tools }\end{array}$} & Improved communication means & 13 \\
\hline & Round-the-clock development & 8 \\
\hline & Different cultures & 6 \\
\hline & Different working styles & 3 \\
\hline \multirow[t]{3}{*}{ Firing supplier } & Legal issues & 14 \\
\hline & Cost & 8 \\
\hline & Scheduling issues & 5 \\
\hline \multirow[t]{3}{*}{ Methodology selection } & $\begin{array}{l}\text { Uncertainty about real competence about a given } \\
\text { methodology in GSD team }\end{array}$ & 8 \\
\hline & $\begin{array}{l}\text { Uncertainty about the success of the methodology in a } \\
\text { cross cultural environment }\end{array}$ & 7 \\
\hline & $\begin{array}{l}\text { Inflexibility and rigidity of the methodology when } \\
\text { applied to a GSD environment }\end{array}$ & 5 \\
\hline \multirow[t]{3}{*}{$\begin{array}{l}\text { Selecting internal } \\
\text { personnel }\end{array}$} & $\begin{array}{l}\text { Need to count on a personnel flexible, with knowledge } \\
\text { about other cultures and devoted to the project }\end{array}$ & 8 \\
\hline & Personnel stability issues (threat of job loss) & 7 \\
\hline & Others & \\
\hline
\end{tabular}


TABLE 3

Hard decisions and differential factors in GSD ranking

\begin{tabular}{|c|c|c|c|}
\hline Decision & Factor & Decision rank & Factor rank \\
\hline \multirow[t]{3}{*}{ Partner-Supplier election } & & 1 & \\
\hline & Trust & & 1.1 \\
\hline & Legal Constraints & & 1.2 \\
\hline \multirow{3}{*}{$\begin{array}{l}\text { Work packages } \\
\text { assignation }\end{array}$} & & 2 & \\
\hline & Software and Task dependencies & & 2.1 \\
\hline & $\begin{array}{l}\text { Need to preserve core competency } \\
\text { in one of the companies }\end{array}$ & & 2.2 \\
\hline \multirow{3}{*}{$\begin{array}{l}\text { Choose coordination } \\
\text { mechanisms \& tools }\end{array}$} & & 3 & \\
\hline & Improved communication means & & 3.1 \\
\hline & Different cultures & & 3.2 \\
\hline \multirow[t]{3}{*}{ Firing supplier } & & 4 & \\
\hline & Legal Issues & & 4.1 \\
\hline & Costs & & 4.2 \\
\hline \multirow[t]{3}{*}{ Methodology selection } & & 5 & \\
\hline & $\begin{array}{l}\text { Uncertainty about real competence } \\
\text { about a given methodology in } \\
\text { GSD team }\end{array}$ & & 5.1 \\
\hline & $\begin{array}{l}\text { Inflexibility and rigidity of the } \\
\text { methodology when applied to a } \\
\text { GSD environment }\end{array}$ & & 5.2 \\
\hline
\end{tabular}

ranked in the same order than in Phase 1. Additionally, regarding to differential factors the order of the first of them always coincides with the correspondent in Phase 1 whereas, the latter three factors out of five have been identically expressed in both Phases. Furthermore, this circumstance is supported by the fact that the Kendall's coefficient is significantly greater when considering Hard Decisions than considering factors, which indicates a lower consensus level among the panelists.

\section{DISCUSSION}

The first relevant aspect that can be extracted from the results achieved so far is the absence of references to requirements engineering. The interaction of requirements engineering has been subject of recent research (e.g., Bhat, Gupta, \& Murthy, 2006; Damian \& Zowghi, 2003; Damian, 2007). Although it has been pointed out that GSD are an attractive and promising research area (Herbsleb, 2007), the similarity of the process to the traditional development imply that aspects such as prioritization and negotiation are not considered as distinguishing elements in relation to the traditional process. A second relevant element that can be explanatory with regard to the no inclusion of requirements engineering is the composition of the sample. Thus, after the analysis of the results, authors consider that focusing in project managers entails that in most of the cases (specifically in 23 out of 25) the predominant GSD relationship is offshoring outsourcing in which requirement elicitation is developed by the contracting company, which correlates with the irrelevance of the necessity of trusting in third parties for elicitation. Nevertheless, to conclude the requirements argument, the requirements communication has been pointed out as an element to be taken into account in relation to GSD.

The second of the aspects that should be remarked in this study is the relevance of trust. Just as has been stated in different works (e.g., Hernández-López et al., 2010), this element is crucial when it comes to understand the GSD phenomenon, and as such has been considered by the participants in the study. Trust generation mechanisms in this kind of environments is critical and includes several factors, also present in the study, that can be trust promoters such as the existence of a homogeneous international legal framework and the statement of organizational and personal competency of the partners in an irrefutable way to model the dynamics of the work team (Bisconti, Corallo, De Maggio, Grippa, \& Totaro, 2010) and enabling a common repository of competences and references as well as the building of a common knowledge culture (Bakry \& Alfantookh, 2010).

Regarding work packages assignations, in addition to software and task dependencies, element which is present in every software development project, the most relevant circumstance is the necessity of preserving core competency in a distributed 
environment and increasingly competitive. This requirement stems from the characteristics of offshoring outsourcing and has been profusely stated in the literature (e.g., Li, Liu, Li, \& Wu, 2008).

Cultural aspects should also be taking into account in the analysis of GSD. Therefore, this element can be found within coordination mechanisms and tools. Specifically, and according to the comments by several panelists the following is found "communication mechanisms should be established to be respectful towards traditions and cultures to bring together and, if possible, homogenize the communication among participants." Additionally, "communication should be respectful towards national and organizational cultural aspects", as has also been reported in the literature (Carmel \& Agarwal, 2001).

The selection of a methodology is considered relevant and, as has been stated before, is significantly influenced by the lack of confidence on partner's competency. Thus, in an ecosystem highly influenced by reputation in Internet environments, establishing mechanisms for the publication and ascertainment of partners' references and competency is considered fundamental. At last, regarding inflexibility of methodology, this element is a traditional one in software engineering and the emergence of agile methodologies has not contributed to the fully resolution of the problem, being this a hard decision evidenced by the dilemma between rigidity and lack of rigor in the application of the methodology.

\section{CONCLUSIONS}

According to the results obtained from the empirical research developed, a relevant parallelism can be found in hard decision making in management of both conventional and GSD teams. This is supported by the fact that the top three decisions in the elaborated ranking are partner-supplier election, work packages assignation and coordination mechanisms and tools selection, which can be found in the most relevant decisions in conventional development team environments.

Authors believe that further effort should be directed towards the analysis of relevant elements that should be considered when facing hard decisions in GSD environments. This effort could be subsequently transformed into a checklist for project managers to record and state the characteristics of each GSD project enabling them to identify the factors that could alleviate, or even remove, the hard decisions to be taken.

Finally, the capitalization of this work should be accomplished by the development of a training and support solution for hard decisions in GSD projects. Decision making is an interpersonal competence that can be developed via training. Taking this into account, knowing the implications and scenarios of hard decisions in GSD environments can be considered a crucial step to enable an enhanced management training in GSD projects. The potential of the solution would be increased by enabling the adaptability of the scenarios to the precise requirements and context of each organization and the position and competency profile of the trainee. As a support solution, the platform would provide project managers with an interactive version of the aforementioned checklist, with simulation tools to represent the possible consequences of a hard decision (or a set of them) and with a list of measures, actions and tasks to be developed after the decision to fully accomplish the effect of the decision.

\section{AUTHOR BIOS}

Angel García-Crespo is the Head of the SofLab Group at the Computer Science Department in the Universidad Carlos III de Madrid and the Head of the Institute for promotion of Innovation Pedro Juan de Lastanosa. He holds a PhD in Industrial Engineering from the Universidad Politécnica de Madrid and received an Executive MBA from the Instituto de Empresa. Professor García-Crespo has led and actively contributed to large European Projects and also in many business cooperations. He is the author of more than a hundred publications in conferences, journals and books, both Spanish and international.

Ricardo Colomo-Palacios is an Associate Professor at the Computer Science Department of the Universidad Carlos III de Madrid. His research interests include applied research in Information Systems, Software Project Management, People in Software Projects and Social and Semantic Web. He received his $\mathrm{PhD}$ in Computer Science from the Universidad Politécnica of Madrid (2005). He also holds a MBA from the Instituto de Empresa (2002). He has been working as software engineer, project manager and software engineering consultant in several companies including Spanish IT leader INDRA. He is also an Editorial Board Member and Associate Editor for several international journals and conferences and Editor in Chief of International Journal of Human Capital and Information Technology Professionals.

Pedro Soto-Acosta is a Professor of Management at the University of Murcia (Spain). He holds a $\mathrm{PhD}$ in Management Information Systems (MISs) and a Master's degree in Technology Management from the University of Murcia. He received his BA in Accounting and Finance from the Manchester Metropolitan University (UK) and his BA in Business Administration from the University of Murcia. He attended Postgraduate Courses at Harvard University (USA). His work has been published in journals such as the European Journal of Information Systems, the International Journal of Information Management, the Information Systems Management, and the Journal of Enterprise Information Management, among others.

Marcos Ruano-Mayoral is a consultant at EGEOIT, Spain. Formerly he was a Research Assistant of the Computer Science Department at Universidad Carlos III de Madrid. He holds a BSc in Computer Systems from Universidad de Valladolid and an MSc in Computer Science from Universidad Carlos III de Madrid. He has been involved in several research projects as information management engineer and software consultant. 


\section{REFERENCES}

Bakry, S.H., \& Alfantookh, A. (2010). Toward Building the Knowledge Culture: Reviews and a KC-STOPE with Six Sigma View. International Journal of Knowledge Society Research, 1 (1), 47-65.

Bhat, J.M., Gupta, M., \& Murthy, S.N. (2006). Overcoming Requirements Engineering Challenges: Lessons from Offshore Outsourcing. IEEE Software, 23 (5), 38-44.

Bisconti, C., Corallo, B., De Maggio, M., Grippa, F., \& Totaro, S. (2010). Quantum Modeling of Social Dynamics. International Journal of Knowledge Society Research, 1 (1), 1-12.

Carmel, E. \& Agarwal, R. (2001). Tactical Approaches for Alleviating Distance in Global Software Development. IEEE Software, 18 (2), 22-29.

Clemen, R.T. (1996). Making Hard Decisions: An Introduction to Decision Analysis, 2nd ed. Belmont, CA: Duxbury Press.

Clemen, R.T., \& Reilly, T. (2001). Making hard decisions with decision tools. Belmont, CA: Duxbury Press.

Cusick, J., \& Prasad, A. (2006). A Practical Management and Engineering Approach to Offshore Collaboration. IEEE Software, 23 (5), 20-29.

Dalkey, N., \& Helmer, O. (1963). An experimental application of the delphi method to the use of experts. Management Science, 9, 458-467.

Damian, D., (2007). Stakeholders in Global Requirements Engineering: Lessons Learned from Practice. IEEE Software, 24 (2), 21-27.

Damian, D., \& Moitra, D. (2006). Global software development: How far have we come? IEEE. Software, 23 (5), 17-19.

Damian, D.E. \& Zowghi, D. (2003). Requirements Engineering challenges in multi-site software development organizations. Requirements Engineering Journal, 8 (3), 149-160.

Ebert, C., \& De Naeve, P. (2001). Surviving Global Software Development. IEEE Software, 18 (2), 62-69.

Herbsleb, J.D. (2007). Global Software Engineering: The Future of Sociotechnical Coordination. In L. C. Briond and A. L. Wolf (Eds.) Proceedings of the International Conference on Software Engineering (pp. 188-198). Los Alamitos: IEEE Computer Society Press.

Herbsleb, J.D., \& Moitra, D. (2001). Guest editor's introduction: Global software development. IEEE Software, 18 (2), 16-20.

Hernández-López, A., Colomo-Palacios, R., García-Crespo, A., \& Soto-Acosta, P. (2010). Trust Building Process for Global Software Development Teams. A review from the Literature. International Journal of Knowledge Society Research, 1 (1), 66-83.

Hinds, P. J., \& Bailey, D. E. (2003). Out of sight, out of synch: Understanding conflict in distributed teams. Organization Science, 14(6), 615-632.

Holsapple, C.W., \& Joshi, K.D. (2002). Knowledge manipulation activities: results of a Delphi study. Information \& Management, 39 (6), 477-490.

Hsu, Y.L., Lee, C.H., \& Kreng, V.B. (2010). The application of fuzzy delphi method and fuzzy AHP in lubricant regenerative technology selection. Expert Systems with Applications, 37 (1), 419-425.

Keil, M., Tiwana, A., \& Bush, A. (2002). Reconciling user and project manager perceptions of IT project risk: a Delphi study. Information Systems, 12(2), 103-119.

Klein, H.K., \& Myers, M.D. (1999). A set of principles for conducting and evaluating interpretive field studies in information systems. MIS Quarterly, 23(1), 67-93.

Lai, V.S., \& Chung, W. (2002). Managing international data communications. Information \& Management, 45 (3), 89-93.

Li, Y., Liu, Y., Li, M., \& Wu, H. (2008). Transformational offshore outsourcing: empirical evidence from alliances in China. Journal of Operations Management, 26 (2), pp. 257-274.

Lytras M., \& Ordóñez de Pablos, P. (2007). Red Gate Corner: a Web 2.0 prototype for knowledge and learning concerning China business and culture. International Journal of Knowledge and Learning, 3 (4\&5), $542-548$.

Lytras, M.D., \& Ordóñez de Pablos, P. (2008a). Competencies and Human Resource Management: Implications for Organizational Competitive Advantage. Special Issue on "“'Competencies Management: Integrating Semantic Web and Technology-Enhanced Learning Approaches for Effective Knowledge Management. Journal of Knowledge Management, 12 (6), 48-55.

Lytras, M.D., \& Ordóñez de Pablos, P. (2008b). The role of a "make" or internal human resource management system in Spanish manufacturing companies: empirical evidence. Human Factors and Ergonomics in Manufacturing, 18 (4), 464-479.

Lytras, M.D., Sakkopoulos, E., \& Ordóñez de Pablos, P. (2009). Semantic Web and Knowledge Management for the health domain: state of the art and challenges for the Seventh Framework Programme (FP7) of the European Union (2007-2013). International Journal of Technology Management, 47 $(1 / 2 / 3), 239-249$.

Moløkken-Østvold, K., \& Jørgensen, M. (2004). Group Processes in Software Effort Estimation. Empirical Software Engineering, 9 (4), 315-334.

Myers, M.D. (1997). Qualitative Research in Information Systems. MIS Quarterly, 21 (2), 241-242.

Nevo, D., \& Chan, Y.E. (2007). A Delphi study of knowledge management systems: Scope and requirements. Information \& Management, 44 (6), 583-597.

Okoli, C., \& Pawlowski, S.D. (2004). The Delphi method as a research tool: an example, design considerations and applications. Information \& Management, 42 (1), 15-29.

Ordóñez de Pablos, P. (2002). Knowledge management and organizational learning: Typologies of generic knowledge strategies in the Spanish manufacturing industry from 1995 to 1999. Journal of Knowledge Management, $6(1), 52-62$

Oshri, I., Kotlarsky, J., \& Willcocks, L. P. (2007). Global Software Development: Exploring socialization in distributed strategic projects. Journal of Strategic Information Systems, 16 (1), 25-49.

Prikladnicki, R., Nicolas Audy, J.L., \& Evaristo, R. (2003). Global Software Development in Practice Lessons Learned. Journal of Software Process: Improvement and Practice, 8 (4), 267-281.

Rodriguez Pérez, J.M., \& Ordóñez de Pablos, P. (2003). Knowledge management and organizational competitiveness: A framework for human capital analysis. Journal of Knowledge Management, 7 (3), 82-91.

Rose, J., Pedersen, K., Hosbond, J. H., \& Kræmmergaard, P. (2007). Management competences, not tools and techniques: A grounded examination of software project management at WM-data. Information and Software Technology, 49 (6), 605-624.

Schmidt, R.C. (1997). Managing Delphi surveys using nonparametric statistical techniques. Decision Sciences, 28 (3), 763-774.

Schmidt, R.C., Lyytinen, K., Keil, M., \& Cule, P. (2001). Identifying software project risks: an international Delphi study. Journal of Management Information Systems, 17 (4), 5-36.

Siegel, S. (1956). Nonparametric Statistics for the Behavioral Sciences. New York: McGraw-Hill.

Sommerville, I., \& Rodden, T. (1996). Human social and organizational influences on the software process, In A. Fuggetta, A. Wolf (Eds.) Software Process. (Trends in Software, 4). (pp. 89-110). New York, NY: John Wiley \& Sons.

Treinen, J.J., \& Miller-Frost, S.L. (2006). Following the sun: Case studies in global software development. IBM Systems Journal, 45 (4), 773-783. 